\title{
Increasing role of arthropod bites in tularaemia transmission in Poland - case reports and diagnostic methods
}

\author{
Kamila Formińska', Aleksandra A Zasada', Waldemar Rastawicki', Karolina Śmietańska', \\ Dorota Bander ${ }^{2}$, Marta Wawrzynowicz-Syczewska², Mariya Yanushevych ${ }^{5}$, \\ Jolanta Niścigórska-Olsen ${ }^{3}$, Marek Wawszczak ${ }^{4}$ \\ ${ }^{1}$ National Institute of Public Health - National Institute of Hygiene, Department of Bacteriology, Warsaw, Poland \\ 2 Pomeranian Medical University, Clinic of Infectious Diseases, Hepatology and Liver Transplantation, Szczecin, Poland \\ ${ }^{3}$ Regional Szczecin Hospital, Unit of Infectious and Tropical Diseases and Adquired Immunodeficiencies, Szczecin, Poland \\ ${ }^{4}$ Independent Public Central Clinical Hospital, Clinic of General and Endocrinological Surgery, Warsaw, Poland \\ ${ }^{5}$ Medical University of Warsaw, Department of Pediatric Pulmonology and Allergy, Warsaw, Poland
}

Formińska K, Zasada AA, Rastawicki W, Śmietańska K, Bander D, Wawrzynowicz-Syczewska M, Yanushevych M, Niścigórska-Olsen J, Wawszczak M. Increasing role of arthropod bites in tularaemia transmission in Poland - case reports and diagnostic methods. Ann Agric Environ Med. 2015; 22(3): 443-446. doi: 10.5604/12321966.1167711

\begin{abstract}
The study describes four cases of tularaemia - one developed after contact with rabbits and three developed after an arthropod bite. Due to non-specific clinical symptoms, accurate diagnosis of tularaemia may be difficult. The increasing contribution of the arthropod vectors in the transmission of the disease indicates that special effort should be made to apply sensitive and specific diagnostic methods for tularaemia, and to remind health-care workers about this route of Francisella tularensis infections. The advantages and disadvantages of various diagnostic methods - molecular, serological and microbiological culture - are discussed. The PCR as a rapid and proper diagnostic method for ulceroglandular tularaemia is presented.
\end{abstract}

\section{Key words}

tularaemia, arthropods bite, F. tularensis, PCR

\section{INTRODUCTION}

Tularaemia is a serious infectious zoonotic disease, also known as rodent plaque or rabbit fever, caused by a gramnegative, highly virulent, intracellular bacterium called Francisella tularensis [1]. Depending on the site of infection, tularaemia can take six characteristic clinical forms: ulceroglandular, glandular, oropharyngeal, pneumonic, oculoglandular, and typhoidal [2]. Small mammals such as voles, mice, squirrels, and rabbits are natural reservoirs for $F$. tularensis. [3]. Humans can become infected by direct contact with an infected animal (through broken skin, scratch or tissue injury), through aerosols (inhalation of infected dust), by eating infected food, drinking infected water, or through the bite of haematophagous arthropods. [4]. Several natural arthropod vectors have been reported, e.g. fleas, lice, midges, bedbugs, mosquitoes and ticks [5]. Increased exposure to tick bites during the summer and autumn periods may increase spreading of the disease between humans and animals. Also, as a results of climatic changes and the human impact on the environment, the prevalence of ticks and tick-borne infections is expected to increase [6].

The study presents four cases of tularaemia in Poland three developed after an arthropod bite and one after contact with rabbits. The cases were confirmed by serological and molecular investigations and the usefulness of the diagnostic methods is discussed.

Address for correspondence: Kamila Formińska, National Institute of Public Health- National Institute of Hygiene, Department of Bacteriology, Chocimska 24, 00-791 Warsaw, Poland

E-mail: kforminska@pzh.gov.pl

Received: 13 March 2014; accepted: 09 October 2014

\section{CASE REPORTS}

Case 1. In October 2012, a 6-year-old boy was admitted to hospital in Warsaw due to lack of effects in the treatment of inflammation of the cervical lymph nodes, and suspected of Mycobacterium tuberculosis infection. Two weeks before developing the symptoms, the patient had spent his holiday on a farm in the north of Poland where he had frequent contact with domestic rabbits. About month before hospitalization, the boy observed a painless tumour on the right side of his neck and fever of $39^{\circ} \mathrm{C}$. Oral treatment with cephalosporin second generation was applied. After five days, clarithromycin was included and a partial regression of symptoms was observed. However, the patient still had cervical lymphadenopathy. In the fifth day after treatment completion, fever recurrence was observed and lymphadenitis and inflammation of neck soft tissue were diagnosed. Despite treatment with cephalosporin third generation, vancomycin, metronidazole and clarithromycin, deterioration of clinical symptoms was observed: tissue necrosis, multiple neck abscesses and abscess of the parapharyngeal space.

In laboratory tests, slightly raised indexes of inflammation, CRP about $4 \mathrm{mg} / \mathrm{l}$ (upper normal range $1 \mathrm{mg} / \mathrm{l}$ ) and small leukocytosis were found. Examination of purulent contents of lymph nodes biopsy indicated inflammatory granulation tissue with necrosis focuses. Bacteriological culture for aerobic and anaerobic bacteria was negative. Toxoplasmosis and HIV infection were also excluded. Molecular tests for Mycobacterium tuberculosis complex were positive only from wound purulent secretion. Due to the positive test for Mycobacterium tuberculosis complex the patient was treated with isoniazid, rifampicin, pyrazinamide. There 
was no improvement in the health status of the patient. Another genetic test taken from stomach washings was negative. Results of the tuberculin reaction and Interferon Gamma Release Assay (IGRA) were also negative, and RTG of the chest did not reveal any irregularities. These allowed the exclusion of tuberculosis and the antimycobacterial treatment was discontinued. Serological investigations revealed a high level of antibodies to F. tularensis, diagnosed by tube agglutination test and ELISA (IgA, IgG and IgM). Additionally, elevated levels of IgG (but not IgM) antibodies to Bartonella henselae (cat-scratch fever) were also found in the tested serum. Serological tests for actinomycosis and atypical bacterial infection were negative.

PCR from the lymph nodes biopsy sample revealed DNA of F. tularensis ssp. holarctica. On the basis of above results, ulceroglandular tularaemia was diagnosed and antibiotic therapy changed to streptomycin in a dose of $15 \mathrm{mg} / \mathrm{kg}$ b.w for 10 days. Because of minor improvement, ciprofloxacin in a dose of $15 \mathrm{mg} / \mathrm{kg}$ b.w was applied over the next 10 days. The abscesses were surgically removed. Microbiological examination of histopathological samples taken from the removed abscesses revealed gram negative rods in the samples. After 20 days of treatment, significant regression of symptoms was observed. During the subsequent months condition of the patient further improved.

Case 2. In October 2012, a 55- year-old woman was admitted to hospital in Szczecin, north-west Poland, in the third week of sickness, which had began with headache, fever with chills and muscles pain. The symptoms appeared after an insect bite in the right shin. At the site of the bite, an itchy lump formed. Lymphadenopathy was diagnosed in the right inguinal region. Initially, the patient was treated with amoxicillin and ciprofloxacin, but no improvement was observed. During hospitalization, a dry cough, irritation of conjunctivas, enlarged lymph nodes in the inguinal region were observed. Blood cell count indicate high inflammation parameters CRP $35.94 \mathrm{mg} / \mathrm{l}$, fibrinogen $97.9 \mathrm{~g} / \mathrm{l}$, D-dimer $3642 \mu \mathrm{g} / \mathrm{l}$. Leukocytosis was not diagnosed. A purulent efflux was observed during the surgical intervention of the lymph nodes in the inguinal region. Histological examination showed purulent inflammation with granules characteristic for infection of $F$. tularensis. Serological tests were positive for tularaemia, and PCR revealed F. tularensis ssp. holarctica in the lymph nodes. Bacteriological culture was negative. Combined treatment with ciprofloxacin, gentamicin, doxycycline and streptomycin was applied. During hospitalization, itchy skin, hearing deterioration and buzzing in the ears were notified by the patient. The patient left the hospital after 9 days in good condition.

Case 3. In June 2013, a 33-year-old man who had spent several days on a bike trip and camping noticed a small suppurating pathological change on the occiput which persisted for 3 weeks. The patients reported to a hospital in Warsaw due to pain in the right subclavicular region. Ultrasonography showed enlarged lymph nodes. Histological examination of the lymph nodes showed numerous necrotic focuses surrounded by histiocytic infiltration and giant polynuclear cells. CRP level was $30 \mathrm{mg} / \mathrm{l}$. No other abnormalities in blood parameters were revealed. The tuberculin test and mycobacterial culture were negative. On the basis of results of serological tests for tularaemia and PCR results revealing
DNA of F. tularensis ssp. holarctica in the lymph nodes, ulceroglandular tularemia was diagnosed. Bacteriological culture was negative. The patient was successfully treated with doxycycline for 10 days and ciprofloxacin for 3 weeks.

Case 4. In September 2013, a 64-year-old man was admitted to a hospital in Szczecin with an ulcer of the left shin with inflammatory reaction (size $4 \mathrm{~cm}$ ) (Fig. 1), and with painful swollen lymph nodes of the left groin (size $3 \mathrm{~cm}$ ) without flare, after 3 weeks fever of $37^{\circ} \mathrm{C}$. Ulceration had appeared a

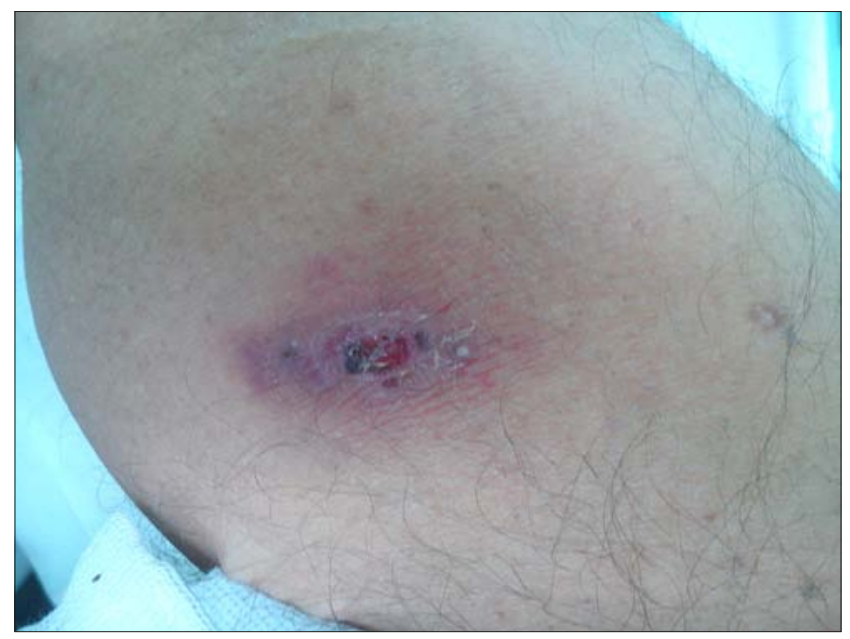

Figure 1. An ulcer of the left shin in Case 4 on the day of admission to the hospital

few days after an insect bite in the left shin. The patient was treated orally with azithromycin, cefuroxime axetil and amoxicillin-clavulanate. Blood cell count determination showed leucocytosis $10.8 \times 10^{3} / \mu \mathrm{l}$, CRP increasing to $41.93 \mathrm{mg} / \mathrm{dl}$, slight increase of LDH: 239U/l, fibrinogen $4.79 \mathrm{~g} / \mathrm{l}, \mathrm{D}$-dimer $2270 \mu \mathrm{g} / \mathrm{l}$. Ultrasonography of the lymph nodes of the left shin showed an area of $2.2 \times 1 \mathrm{~cm}$ with peripheral vascular flow and partial disintegration of lymph nodes. Additional treatment was applied with streptomycin of $1 \mathrm{~g}$ intramuscularly and ciprofloxacin intravenously $2 \times 400 \mathrm{mg}$. A biopsy from the left lymph node was taken for culture and molecular tests. In a serum sample, a high level of specific anti-F. tularensis IgA, IgG and IgM antibodies were found. A molecular investigation by PCR and serological tests confirmed ulceroglandular tularaemia caused by F. tularensis ssp. holarctica. Culture for F. tularensis was negative. Ciprofloxacin treatment was finished after 7 days, streptomycin treatment was extended to 18 days because of persistent lymphadenopathy. The patient left the hospital after 18 days with regression of symptoms. (Fig. 2).

Tularemia antibodies in serum samples from all the patients were tested by the tube agglutination test, home-made ELISA with sonicated antigen of $F$. tularensis and commercial assay Francisella tularensis IgG/IgM Serion ELISA classic (Institut Virion/Serion GmbH, Germany) with lipopolysaccharides of F. tularensis, as described previously [7].

DNA from the swabs from a lymph node, and from the lymph node aspirates was extracted using a High Pure PCR Template Preparation Kit (Roche), according to the manufacturer's instructions.

PCR for detection of F.tularensis DNA and subspecies identification was conducted as described previously [8]. 


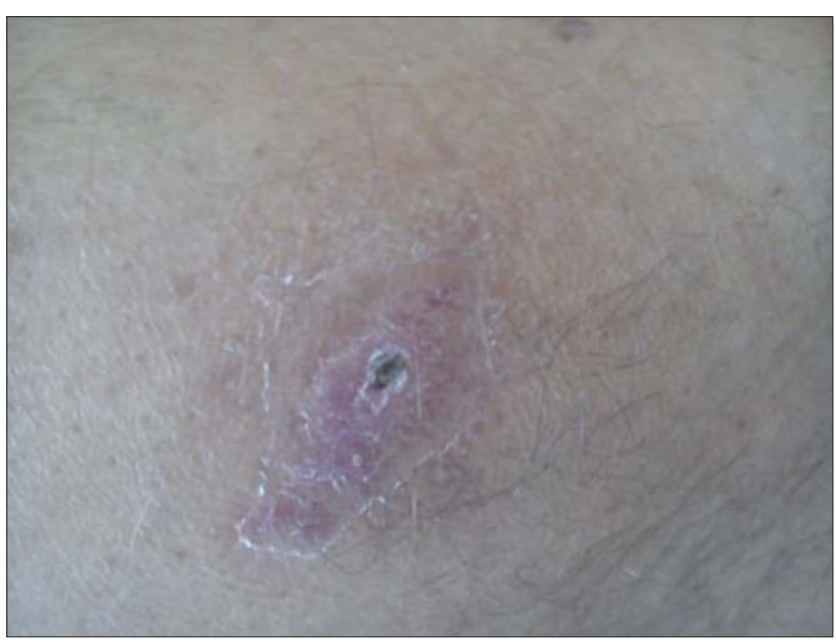

Figure 2. An ulcer of the left shin in Case 4 on 10th day after initiation of therapy

The samples from the lymph nodes were also inoculated onto Columbia Agar with 5\% sheep blood and onto Cysteine Heart Agar plates. The plates were incubated at $37^{\circ} \mathrm{C}$ in $5 \%$ $\mathrm{CO}_{2}$ for 10 days. Culture was conducted in laboratory BSL3.

\section{DISCUSSION}

Tularaemia is endemic in most European countries[9], and in EU countries the number of reported cases is usually less than 1,000 per year. In some areas, like Finland or Sweden, outbreaks comprising more than 100 cases are reported every 10 years. For example, in 2006-2010, epidemics were observed in Finland where 1,490 cases were confirmed (400 cases recorded in 2006, 2007 and 2009 in each year) and in Sweden, where 1,525 cases were reported [1]. In other European regions outbreaks occur sporadically. According to the NIZP-PZH [10] data for 1996-2013, 52 cases of tularaemia were reported, 6 and 8 cases were reported in 2012 and 2013, respectively [11]. In the last 50 years, most reported cases of tularaemia in Poland had septic or typhoidal forms and were acquired by handling hares [11]. Transmission of tularaemia via mosquito bite was repeatedly described from Scandinavia, but not from Central Europe [12]. Nowadays, the most common form of tularaemia in Poland is ulcerogolandular or glandular, often developing after an arthropod bite [11]. The presented study describes three tularaemia cases which resulted from arthropod bites, and only one case resulting from contact with hares. Also in other European countries, tularaemia cases acquired through an arthropod bite were reported recently, e.g. in Germany [12] and Spain [13].

Diagnosis of tularaemia is based mainly on serological methods due to difficulties with the culture of $F$. tularensis from clinical samples [11].

The advantages of serological methods are easiness of obtaining diagnostic samples and rapidity of the tests, compared to microbiological culture. However, serological tests are negative during the first two weeks following the onset of symptoms, which means that diagnosis may not be possible in the early stages of infection. Moreover, positive serological tests may confirm infection or may indicate previous direct contact with the pathogen. A four-fold rise in antibody titers is consider diagnostic for tularaemia infection, but it require two samples, obtained at a two-weeks interval. $[14,15]$. Another disadvantage of the serological method is the risk of cross-reactivity between the F. tularensis closelyrelated pathogens Brucella sp., Proteus sp., and Yersinia sp. [16]

Culture of a pathogen is usually regarded as the 'gold standard;' for diagnosis of infections. However, culture of F. tularensis is difficult as the bacterium is slow-growing (up to 10 days) and requires special media and culture conditions. Furthermore, attempts to culture F. tularensis pose a significant risk of infection for laboratory personnel and should be conducted under BSL3 conditions [17]. The chance for positive culture decreases significantly when the sample is taken after the beginning of antibiotic therapy. Molecular investigation by PCR method is a much better tool for laboratory diagnosis of tularaemia.

In the presented study, F. tularensis in lymph nodes specimens taken from patients was successfully detected when the antibiotic therapy was in progress. Moreover, the PCR enabled identification of subspecies of the bacterium, which is very important because the course and severity of the disease is associated with a level of virulence of the pathogen related to subspecies. F. tularensis is divided into four subspecies, among which two of them, F.tularensis ssp. tularensis (type A) and ssp. holarctica (type B), are predominantly isolated [9]. Type $\mathrm{A}$ is the most virulent and has an infectious dose of $<10 \mathrm{CFU}$ in humans, and can lead to life-threatening illness, particularly when infection occurs via the respiratory route $[18,19]$. Type B is less-virulent, causes a milder form of tularaemia which is only rarely lethal to humans, and has an infectious dose of $<10^{3} \mathrm{CFU}$ [19]. Of the other two subspecies, one, F. tularensis ssp. novicida, is infrequently associated with human disease in some regions of North America and Australia, and the other, F. tularensis ssp. madiaasiatica, has not been associated with human diseases [20, 21,22,23].

The rapid and relatively inexpensive PCR method for tularaemia diagnosis is also useful for differentiating it from other infections with similar manifestations. For example, mycobacterial disease was suspected in some of the presented cases as it may present with the same kind of local lymphadenopathy as tularaemia. If the lymph nodes reveal necrotizing granulomatous inflammation, the patient may undergo unnecessary long-term antituberculosis treatment [24]. Moreover, in the differential diagnosis of necrotizing lymphadenitis, the following must be considered: staphylococcal and streptococcal infections, cytomegalovirus, Epstein-Barr virus (mononucleosis), mycobacteriosis, toxoplasmosis, lymphoma, brucellosis, and tularaemia [23]. Other forms and manifestations of tularaemia should be differentiated from leukemia, catscratch disease, pulmonary tuberculosis, plague, pulmonary anthrax, atypical pneumonia, Q fever, ornithosis, typhoid fever, leptospirosis and SARS [25].

Rapid and proper diagnosis is essential for effective therapy of tularaemia. F. tularensis is resistant to betalactam antibiotics, and such treatment may lead to a chronic disease process $[14,15]$. Aminoglycosides, ciprofloxacin and doxycycline are recommended for the treatment of tularaemia treatment [26].

The presented cases confirm the limited usefulness of microbiological culture in tularaemia diagnosis, as F. tularensis is a fastidious, slow-growing organism [27]. Samples for culture were taken after initial antibiotic therapy 
which additionally influenced the culture negatively. PCR was demonstrated to be a very useful method in tularaemia diagnosis as it is rapid, positive results are possible also after initial antibiotic therapy, and it is safe for laboratory personnel because heating clinical samples before testing prevents laboratory-acquired infections, and does not influence the results [17]. To the best of the knowledge of the authors of the current study, the presented cases were confirmed for the first time in Poland by methods other than serological methods.

\section{CONCLUSIONS}

Tularaemia is a rare disease in Poland but it could be underestimated. A special effort should be made to remind health-care workers that $F$. tularensis infections may occur not only through direct contact with animals, but also via arthropod bites. Camping, forest and park trips may also be a risk of tularemia acquisition.

The best diagnostic method to identify the subspecies in tularaemia is PCR. The advantages of this method are rapidity, reliable results even in the early stages of the disease, and after initiation of antibiotic therapy, as well as the possibility to identify the subspecies of F.tularensis which allows determination of the level of pathogenicity and infectivity.

\section{REFERENCES}

1. Pilo P, Johansson A, Frey J. Identification of Francisella tularensis cluster in central and western Europe. Emerg Infect Dis. 2009; 15(12): 2049-2051.

2. Plourde PJ, Embree J, Friesen F, Lindsay G, Williams T. Glandular tularemia with typhoidal features in a Manitoba child. CMAJ. 1992; 146(11): 1953-1955.

3. Dennis DT, Inglesby TV, Henderson DA, Bartlett JG, Ascher MS, Eitzen E, et al. Tularemia as a biological weapon: medical and public health management. JAMA. 2001; 285(21): 2763-2773.

4. Franke J, Fritzsch J, Tomaso H, Straube E, Dorn W, Hildebrandt A, et al. Coexistence of pathogens In host-seeking and feeding ticks within a single natural habitat In central Germany. Appl Environ Microbiol. 2010; 76(20): 6929-6836.

5. Gehringer H, Schacht E, Maylaender N, Zeman E, Kaysser P, et al. Presence of an emerging subclone of Francisella tularensis holarctica in Ixodes ricinus ticks from south-western Germany. Ticks Tick Borne Dis. 2013 ; 4(1-2): 93-100.

6. Reye AL, Hübschen JM, Sausy A, Muller CP. Prevalence and seasonality of tick- borne pathogens in questing Ixodes ricinus ticks from Luxembourg. Appl Environ Microbiol. 2010; 76(9): 2923-2931.

7. Rastawicki W, Wolaniuk N. Comparison of usefulness of commercial ELISA Virion/Serion, home-made ELISA and tube agglutination test in serodiagnosis of tularemia. Medycyna Doświadczalna I Mikrobilogia 2013; 65: 255-261.
8. Zasada AA, Gierczyński R, Rzeczkowska M, Formińska K, Zacharczuk K, Rastawicki W. Detection and identification of highly pathogenic bacteria within the framework of the EQADeBa project - Part I: Samples containing living pathogens. Przegl Epidemiol. 2011; 65(3): 401-407.

9. Tärnvik A, Priebe HS, Grunow R. Tularemia in Europe: an epidemiological overview. Scand J InfectDis. 2004; 36(5): 350-355.

10. Narodowy Instytut Zdrowia Publicznego-Państwowy Zakład Higieny (NIZP-PZH) http://www.pzh.gov.pl/oldpage/epimeld/2013/index_ mp.html (access: 2014.02.20).

11. Moniuszko A, Zajkowska J, Pancewicz S, Kondrusik M, Grygorczuk S, Czupryna P. Arthroopod - borne tularemia in Poland: A case report. Vector Borne Zoonotic Dis. 2011; 11(10): 1399-1401.

12. Hanke CA, Otten JE, Berner R, Serr A, Splettstoesser W, von Schnakenburg C. Ulceroglandular tularemia in a toddler in Germany after a mosquito bite. Eur J Pediatr. 2009; 168(8): 937-940.

13. Martin C, Gallardo MT, Mateos L, Vián E, Garcia MJ, Ramos J, et al. Outbreak of tularaemia in Castilla y León, Spain. Euro Surveill. 2007; 12(11):E071108.1

14. Dentan C, Pavese P, Pelloux I, Boisset S, Brion JP, Stahl JP, et al. Treatment of tularemia in pregnant woman, France. Emerg Infect Dis. 2013; 19(6): 996-998.

15. Karadağ-Öncel K, Özkaya-Pavlakay A, Özsürekci Y, Ceyhan M, Cengiz $\mathrm{AB}, \mathrm{Kara}$ A. A case of glandular tularemia presenting with prolonged fever and mesenteric lymphadenopathy. Turk J Pediatr. 2013; 55(4): 430-432.

16. Kłapeć T, Cholewa A. Tularemia - wciąż groźna zoonoza. MONZ. 2011; 17(3): 155-160.

17. Maurin M, Castan B, Roch N, Gestin B, Pelloux I, Mailles A, et al. Real-time PCR for diagnosis of oculoglandular tularemia. Emerg Infect Dis. 2010 ; 16(1): 152-153.

18. Rastawicki W, Jagielski M. Tularemia. Post Mikrobiol. 2005; 44(3): 265-273 (in Polish).

19. Pechous RD, McCarthy TR, Zahart TC. Working toward the future: insights into Francisella tularensis pathogenesis and vaccine development. Microbiol Mol Biol Rev. 2009; 73(4): 684-711.

20. Olsufjew N, Meshcheryakova IS. Subspecific taxonomy of Francisella tularensis McCoy and Chapin. Int J Syst Evol Microbiol. 1983; 33: 872-874.(18gr).

21. Farlow J, Smith KL, Abrams M, Lytle M, Keim P. Francisella tularensis strain typing using multiple-locus, variable - number tandem repeat analysis. J Clin Microbiol. 2001; 39(9): 3186-3192.

22. Vodop'yanov AS, Mishan'kin BN, Pavlovich NV, Pichurina NL. Genotypic heterogeneity and geographical diversity of collection strains of Francisella tularensis according to the data of VNTR analysis of their DNA. Mol Gen Mikrobiol Virusol. 2005; 2: 78-86.

23. Versage JL, Severin DDM, Chu MC, Petersem JM. Development of multitarget real-time TaqMan PCR assay for enhanced detection of Francisella tularensis in complex speciments. J Clin Microbiol. 2003; 41(12): 5492-5499.

24. Yildirim S, Turhan V, Kavadenizli A, Önem Y, Kavagöz E, Eroğlu C, et al. Tuberculosis or tularemia? A molecular study in cervical lymphadenitis. Int J Infect Dis. 2014; 18: 47-51.

25. Magdzik W, Naruszewicz-Lesiuk D, Zieliński A. Infectious and parasitic disease. $\alpha$-Medica Press, 2004

26. World Health Organization. WHO guidelines on tularemia. WHO 2007. (WHO/CDS/EPR/2007.7).

27. Petersem JM, Schriefer ME, Gage KL, Montenieri JA, Carter LG, Stanley M, et al. Methods for enhanced culture recovery of Francisella tularensis. Appl Environ Microbiol. 2004; 70(60): 3733-3735. 